globin, the oxygen-carrier of the blood, and prevents it from giving off oxygen after it has taken it up. When the blood is exposed to the vapour of the drug as it passes through the lungs, the oxygen becomes

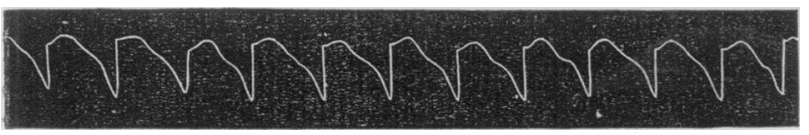

FIG. I.

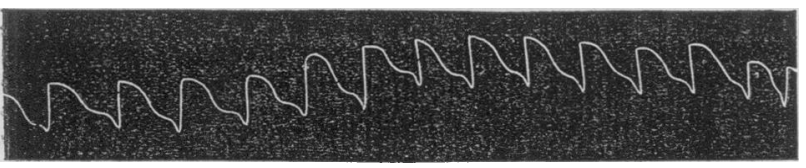

FIG. II.

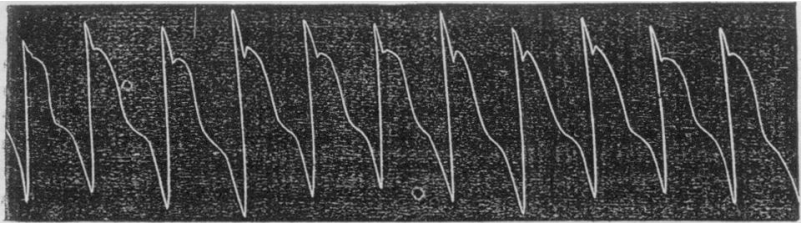

Fig. III.

locked up in it, and cannot be given off to the tissues for their use, so that however much oxygen the blood in the arteries may contain, it acts very much as if it were venous. In consequence of this, I have found that, when the vapour of the nitrite is passed into the lungs of rabbits, they are seized with suffocative convulsions. The greater part of the blood which passed through the lungs having been acted on by the vapour, it affects the brain just as it would have done if the trachea had been closed, and no air allowed to come near it during its passage through the pulmonary vessels, and therefore convulsions occur as soon as it reaches the brain. Professor H. C. Wood of Philadelphia, who has lately written a valuable paper on the action of the nitrite, found no convulsions after injecting it subcutaneously. By giving it in this way, the blood was not acted on during its passage through the lungs, and asphyxia was prevented. This, I think, shows that if nitrite of amyl is to be used at all as a remedy in cholera, it must be given in. ternally or by subcutaneous injection, and not by inhalation. This mode of administration seems to me to be indicated also in spasmodic asthma, when the arterialisation of the blood is also impaired. In angina pectoris it will act when given internally, but a larger dose is required than when inhaled; and it remains to be seen whether it can be given in cholera in sufficient doses to relax the capillaries without, at the same time, injuriously impairing the respiratory changes in the blood and tissues.

\section{MOLLUSCUM CONTAGIOSUM.}

\section{BY BALMANNO SQUIRE, M.B.}

IN reference to Dr. Liveing's note on his case of molluscum contagiosum, I may mention that some years ago a series of three cases of this disease occurring in children of one family, and affecting all three within a period of a few weeks, brought the contagiousness of the eruption so clearly before me that it occurred to me to seek a cause for it. I accordingly examined the sebaceous pellet which forms the pulp of the little tumours, with a view to discovering, if possible, the presence of a parasite; although, so far as I am aware, a parasitic nature has never been imputed to this disease.

It will be anticipated that I met at the outset with a very formidable obstacle in the well-known strong refraction of light which is characteristic of parasitic germs, and which renders it difficult to distinguish them from minute oil-globules; and that this peculiarity of fungus-spores would make it by no means easy to search for them in a sebaceous mass of which minute oil-globules are a prevailing constituent. In the diseases of the skin, the parasitic nature of which has been hitherto ascertained (favus, tinea tonsurans, and chloasma), this difficulty does not present itself. It is, therefore, easy in examining the structures (the hair and the epidermis) that are invaded by the parasites proper to these diseases, to determine the presence or absence of the fungi that are known to infest these tissues.

The difficulty which presented itself I, however, contrived to get rid of -as I think, very effectually - by digesting the sebaceous mass for many hours in ether, a process by which the mass was very considerably shrivelled. I then discovered under the microscope what I believe to have been most decided parasitic spores, to which I will not venture to give a botanical name. These spores, if my recollection serves me, were somewhat larger than those of the parasite of favus (Microsporon Audonini). I distinguished them clearly from oil-globules by a feature which I had found to be very characteristic of the large spores of the Microsporon Audonini, namely, that (unlike oil-globules) under a high power (an eighth) their apparently rounded outline, as seen under a quarter-inch power, discloses itself as a faceted (decidedly angular) outline. By this I do not mean that they have sharp angles, but rounded (as if slightly worn) angles. I did not find any mycelium; but, as regards this, I may add that I have never been able to make out any unexceptionable evidence of mycelium in hairs infested, even abundantly, with the spores of the tricophyton tonsurans, although it is plain enough in the Mierosporon Audouini, and also in the Microsporon furfur. I ought to mention, that a distinct oval nucleus, similar to what is presented under a high power by the spores of the Microsporon Audouini, was plainly perceptible also in the fungus that $I$ am imputing to the molluscum contagiosum.

There is another matter which arises from what I have put forth, and which ought not to be omitted : molluscum contagiosum is a disease which presents very anomalous and peculiar features. In no other disease of the skin do sebaceous collections increase with the surprising rapidity that is characteristic of them in this disease. In acne, in noncontagious molluscum, in sebaceous wens, the growth of the sebaceous collection itself is remarkably tardy. But the presence of a parasite will afford the requisite explanation of the difference. If, as I believe, the parasite which I have described be the special vegetable parasite of the sebaceous glands, just as the parasite present in chloasma is the parasite proper of the epidermis, and again as the parasites of favus and of tinea tonsurans are the special parasites of the hairs, - it becomes then no more difficult to understand a rapid formation of sebaceous matter provoked under the irritation of the sebaceous glands set up by the presence of a parasite, than it is to comprehend the rapid formation of scurfy epidermis produced by the irritation of the surface of the cutis by the parasite present in chloasma.

I did not publish my investigation at the time when I made it, being then busy with clinical photography; but I think the research, over which I took some pains, is worth recording, if only to serve as a hint for some more able investigator.

\section{THE USE OF BATHS IN SMALL-POX.}

By CHRISTIAN BAEUMLER, M.D., Assistant-Physician to the German Hospital.

LOokING upon hospitals as our guides in therapeutical matters, I am sure that other members of our profession besides myself must have felt some disappointment at the uncertainty of opinion regarding the above subject, which the medical evidence in the Hampstead Hospital inquiry has brought to light. The statements which were made were not characterised by that confidence which is founded on an exact knowledge whether and when a remedy is suitable or even necessary, or when it is contraindicated.

At the present day, no more doubt or uncertainty ought to exist on so important a point as this; and if it would be unreasonable to expect from any hospital accurate clinical observations on such a question at a time when an epidemic is rapidly spreading or at its height, and when necessarily all the resources of the hospital are strained to the utmost, yet the opportunity to settle this question ought not to be allowed to pass while the epidemic is declining and the hospital staffs are less overworked; for I am afraid we are still very far from the much-desired end of stamping out small-pox altogether, nor is the mortality from it so reduced as to let us lay down our hands in complacency and as to make unnecessary any further endeavours to find out means for reducing it still more.

The beneficial results which follow the use of cooling baths in other fevers can only encourage an attempt in the same direction with small-pox. Any one who has seen how the restlessness of a patient suffering from the initiatory fever of scarlatina, or in any other fever, is quieted by, and how sleep follows upon, a cool bath, cannot help thinking that the same effect would be produced in small-pox whenever the restlessness and delirium are accompanied by high pyrexia, and that, consequently, mechanical restraint would much more rarely become necessary. That the pyrexia had something to do with the delirium of those patients that had to be restrained at Hampstead, I conclude from the fact that this restraint has, in almost all the cases, only been found 

necessary during the night, when naturally the fever would be at its
highest.

I have very little experience of delirium in small-pox, but I should think that in the majority of cases the delirium will chiefly occur during the initiatory fever, and then be accompanied by high pyrexia. It is very probable, however, that in a certain number of cases, and espe. cially with drinkers, delirium of a violent character may also come on at the stage of the crisis, and then have the significance of what Dr. Hermann Weber has called the " delirium of collapse". The treatment in the two cases will, of course, be essentially different-the one requiring cooling, the other stimulating, measures.

In cases of the first category, I have seen baths with cold affusion used in the hospitals of Paris, and this seemed to be the recognised treatment for great restlessness and delirium. Currie, who is too much forgotten in England, used them in small-pox in the last century, and says ( $M c d$. Keports, ii, p. 58): "This, however, I can declare, that in all the cases in which I have used the affusion of cold water during the eruptive fever, however severe the symptoms may have been, these symptoms instantly abated, and the disease assumed a benignant form." And, in conclusion, he remarks that the Chinese are said to have long followed the practice with extraordinary success. Evidence similar to this last remark is given by a Dr. Fischer in the beginning of the last century, of some parts of Hungary and Silesia, where tepid bathing of small-pox patients had long been a popular treatment; this certainly is remarkable, as, upon the whole, those classes which generally suffer most from small-pox are not distinguished by any particular pre. dilection for water.

Cases of hæmorrhagic small-pox, which generally are not accompanied by very high pyrexia and delirium, do, according to two cases related by Currie, not seem to be benefited by the use of cold or tepid affusion.

But sufficient has been said to show the more important bearings of the question; and I venture to express a hope that the profession will soon be in possession of conclusive evidence upon the following points. I. What influence has a systematic reduction of the temperature of the body in small-pox on the delirium accompanying the eruptive stage, and on the further course of the disease? 2. What is the effect of such a treatment, more especially on the eruption? 3. What effect has tepid, or, with high fever, cool bathing in the later stages of the disease on the eruption and on the general state of the patient?

\section{REPORTS}

$$
\text { or }
$$

\section{MEDICAL AND SURGICAL PRACTICE IN THE HOSPITALS OF GREAT BRITAIN.}

\section{REPORT ON THE TREATMENT OF "SICK-HEADACHE" [Continued from page 13 of number for Fan. 6th.] \\ ST. MARY'S HOSPITAL.}

Dr. LAwson says that, so far as he knows, there is no better defined or less understood malady than sick-headache. It is not common at the hospital-that is, in the outdoor department. He is disposed to think it is most frequent in private practice, and is sorry to say from what he knows of it that it is incurable ; that is, not that it cannot be relieved, but that it recurs. In fact, he knows of at least five persons who have it regularly about eight or ten times a year. He does not think it is more frequent in one sex than in the other, and he is not aware that menstruation affects it in the slightest manner. Its symptoms are well known. They are, a violent pain across the front and upper part of the head, with disinclination for food, sickness, and occasionally vomiting. It extends over various periods, extending from twentyfour hours to three or even four days. When the vomiting is severe, the pain comes to an end sooner than when there is no vomiting. Frequently it will be found that the bowels are costive, but this is by no means always the case. People of a bilious temperament are most subject to "sick-headache." As to treatment, he simply recommends the patient to avoid food, and to rest in bed. He allows a certain amount (varying, of course, according to the age and habits of the patient) of alcohol, either brandy or whisky, and administers a good purgative at once. If the case be severe, he promotes vomiting as soon as possible, but generally a good purge is sufficient to carry off the bile, and restore the patient to health. As to the causes of sick-headache, Dr. Lawson does not like to hazard an opinion; he thinks it is due not to any over-action of the liver, but to a reflection of the bile toward the stomach. In fact, he is disposed to think that, owing to the condition of the intestine, the bile does not flow downwards; hence it is propelled toward and into the stomach, and that it is its action on the pneumogastric nerve which promotes the headache. But to what the obstruction is due, he is ignorant. One thing to be avoided is any promise that the patient will not probably have the same complaint again before very long.

Dr. CHEADLE thinks that headache accompanied by bilious vomiting appears to depend upon a morbid irritation of the nervous centres which govern the act of vomiting, accompanied probably by a depression of the vaso-motor centres, which gives rise to increased fulness and pulsation of the vessels of the head. The pain is probably due to increased vascular pressure upon sensory nerve-fibres, rendered hyperæsthetic by the reflex action of the primary cause of irritation. The primary irritation may be in action at the nervous centre itself, or may be applied to the peripheral expansion of an afferent nerve, and thence reflected. In sick-headache of central origin, the phenomena are closely analogous to those met with in meningitis and concussion, with the exception that in the latter case the exciting cause is a serious organic lesion-in the sickheadache a transitory derangement only. There is another analogous form in sea-sickness, although in this the headache is often little marked or absent altogether. Simple sick-headache due to central irritation is, in Dr. Cheadle's experience, extremely rare, but he has met with one very striking instance of it recently. It occurred in the case of an Indian officer who had suffered severe concussion of the brain. He was thrown from his horse, his head struck against a tent-peg in the fall, and he lay many days insensible and in a critical condition. Since that time he has been subject to frequent attacks of violent throbbing headache, accompanied by pulsation of the temporal arteries and bilious vomiting. These attacks are almost invariably brought on by one of two causesa railway journey or a ball. He was at one time in the habit of visiting Brighton for a day once a fortnight, and never escaped the penalty of this journey, although he continued the practice for several months, during which he was under Dr. Cheadle's care. The central disturbance produced by dancing was equally as certain as the shaking of the railway train to produce this unpleasant result. Under ordinary circumstances his health was perfect. With regard to the treatment of central sickheadache, it may be said that drugs exert but little special influence upon the disorder. The various sedatives (with the doubtful exception of bromide of potassium in large doses) fail to give relief. Two or three minims of hydrocyanic acid with four or five grains of carbonate of soda given in two teaspoonfuls of water only (the small quantity of fluid being less liable to rejection by the stomach) may be prescribed with advantage when the retching is excessive. The bowels should be cleared out by a mild purgative. But the best remedies are absolute rest and quiet, and the application of refrigerant lotions to the head. The latter give relief to the symptoms, and with rest and quiet the central equilibrium quickly returns. In an enormous majority of cases, however, headache is due to reflected irritation-to morbid stimulation of the piripheral expansions of afferent nerves distributed to different organs Thus the seat of irritation may be in the stomach, the intestines, and the uterus. The first is a constant source of the disorder, the presence of undigested or unwholesome food, or of food in excessive quantity, being a cause of sick-headache, from which most persons have suffered occasionally. In the same way irritation of the intestines will produce corresponding reflex phenomena. One case which may be quoted in illustration is that of a patient who infallibly suffers from nausea, and violent throbbing headache, whenever by any untoward accident the daily action of the bowels is prevented. The accumulation of freces in the large intestine appears to be the immediate cause, for rapid subsidence of the symptoms follows the evacuation of the bowel, even by a simple enema. The obvious treatment in such cases is to clear out the alimentary canal by a free purge, and soothe the irritated mucous surface by antacids, with small doses of hydrocyanic acid and a light unstimulating diet. The form of disorder which depends upon uterine irritation is less easily remedied. When dependent upon, and coincident with, menstruation, it constantly persists until that period is over. In such cases everything must be done to ease the process, and favour the proper discharge if it be deficient. Warm fomentations to the abdomen, rest in bed, with the hypodermic injection of morphia, or forty grains of bromide of potassium every six hours, have proved the most effectual remedies in Dr. Cheadle's hands. In one or two instances, when all other means had failed, the reflex symptoms have rapidly ceased upon the administration of eight- or ten- minim doses of tincture of Indian hemp. This must be carefully mixed with mucilage to prevent precipitation by the water subsequently added. The neglect of this precaution probably accounts for the reputed uncertainty of action of the drug. According to Dr. Cheadle's experience, the specific effects can always be obtained by proper doses.

Dr. NUNNELEY says that, considering that the headache precedes the vomiting, that the special senses, the heart, the conjunctival vessels, and the nerves of the scalp are all more or less implicated, it would 